\title{
Engaging Elderly People in Telemedicine Through Gamification
}

Frederiek de Vette $^{1}$, MSc; Monique Tabak ${ }^{1,2}, \mathrm{PhD}$; Marit Dekker - van Weering ${ }^{2}, \mathrm{PhD}$; Miriam Vollenbroek-Hutten ${ }^{1,2}$, $\mathrm{PhD}$

${ }^{1}$ University of Twente, Faculty of Electrical Engineering, Mathematics and Computer Science, Biomedical Signals and Systems, Telemedicine group, Enschede, Netherlands

${ }^{2}$ Roessingh Research and Development, Telemedicine Group, Enschede, Netherlands

\section{Corresponding Author:}

Frederiek de Vette, MSc

University of Twente

Faculty of Electrical Engineering, Mathematics and Computer Science, Biomedical Signals and Systems, Telemedicine group PO Box 217

Enschede,

Netherlands

Phone: 31534895591

Fax: 31534892287

Email: a.f.a.devette@utwente.nl

\section{Abstract}

Background: Telemedicine can alleviate the increasing demand for elderly care caused by the rapidly aging population. However, user adherence to technology in telemedicine interventions is low and decreases over time. Therefore, there is a need for methods to increase adherence, specifically of the elderly user. A strategy that has recently emerged to address this problem is gamification. It is the application of game elements to nongame fields to motivate and increase user activity and retention.

Objective: This research aims to (1) provide an overview of existing theoretical frameworks for gamification and explore methods that specifically target the elderly user and (2) explore user classification theories for tailoring game content to the elderly user. This knowledge will provide a foundation for creating a new framework for applying gamification in telemedicine applications to effectively engage the elderly user by increasing and maintaining adherence.

Methods: We performed a broad Internet search using scientific and nonscientific search engines and included information that described either of the following subjects: the conceptualization of gamification, methods to engage elderly users through gamification, or user classification theories for tailored game content.

Results: Our search showed two main approaches concerning frameworks for gamification: from business practices, which mostly aim for more revenue, emerge an applied approach, while academia frameworks are developed incorporating theories on motivation while often aiming for lasting engagement. The search provided limited information regarding the application of gamification to engage elderly users, and a significant gap in knowledge on the effectiveness of a gamified application in practice. Several approaches for classifying users in general were found, based on archetypes and reasons to play, and we present them along with their corresponding taxonomies. The overview we created indicates great connectivity between these taxonomies.

Conclusions: Gamification frameworks have been developed from different backgrounds—business and academia—but rarely target the elderly user. The effectiveness of user classifications for tailored game content in this context is not yet known. As a next step, we propose the development of a framework based on the hypothesized existence of a relation between preference for game content and personality.

(JMIR Serious Games 2015;3(2):e9) doi: 10.2196/games.4561

\section{KEYWORDS}

gamification; framework; elderly; older adults; eHealth; telemedicine; adherence; engagement; classification; player type; personality 


\section{Introduction}

It is expected that $25 \%$ of the European population will be older than 65 years in 2050 because of global population aging [1]. Current socioeconomic structures cannot provide enough work force and capital to meet the needs of this rapidly growing elderly population [2]. Telemedicine refers to health services that enable patients to receive treatment in their daily living environment, whereby distance is bridged by information communication technology (ICT) and at least one health care professional is involved, alleviating the increasing demand for elderly care by extending the time of autonomy and independence [3]. Although telemedicine technology seems promising, practical implementation still leaves much to be desired. Several studies have shown that adherence to telemedicine interventions, such as therapy supporting a healthy lifestyle, is low [4] and decreases over time [5], even though these studies showed a significant effect on health outcomes [6]. Clearly, there is a need for strategies that motivate elderly people to use, and keep using, the technologies offered.

Gamification, the application of game elements to nongame fields, may be such a strategy [7]. There is a rapid growth in the number of initiatives that use gamification, illustrating a variety of approaches developed from various viewpoints, including education, behavior change, physical health, and mental health. However, a lack of a refined conceptualization of this strategy exists in these disciplines, and gamification, for elderly people in particular, remains an even further underexplored area. In general, it is not yet known which one of these approaches is the best for the durable engagement necessary for better adherence.

Choice and personalization of content [8], or tailoring, is known to be beneficial for intrinsic motivation [9], which in turn increases long-term engagement needed for adherence. To provide this tailored content, insight is needed into how users should (or want to) be addressed through gamification and how these needs can be classified is required. To our knowledge, information on the practical implementation of existing classifications is not yet available. We believe that once an overview of existing frameworks for gamification and user classification is established, a gamification strategy that is effective in realizing long-term engagement for the elderly user can be developed.

For this purpose, the aim of the paper is to (1) provide an understanding of the theoretical background of gamification, including existing frameworks for developing gamification both in general and specifically for the elderly population, and (2) explore existing user classification theories that may serve for the tailoring of game content to the target user. Because of the newness of this field of research, we opt for a broad view on activities in gamification that occur not only within but also outside of scientific research. In future research, we will work toward a user classification of the elderly population that can be used to develop evidence-based gamification strategies and tangible design guidelines for gamification in health care.

\section{Methods}

In a succession of 3 Internet searches, a broad approach to the subject of gamification was taken to gain insight into the many developments in gamification that occur both inside and outside of the scientific world. We performed a search in the scientific search engines PubMed, Scopus, and Google Scholar and in diverse nonscientific sources: from game designer blogs and conference videos to MOOCs (massive open online courses) and YouTube videos. In this paper, gamification is defined as the use of elements from games in nongame contexts to improve user experience and engagement without making that system a full game as is the case with serious games including exergames (combination of exercise and gaming) [10,11].

First, we have researched the conceptualization of gamification from a theoretical perspective (see Multimedia Appendix 1). Keywords used in combination with gamification were used, including derivatives of these words: "theory," "definition," "concept," "framework," and "analysis." In addition, keywords (and derivatives of these) implying practical use were used: "method," "application," and "gamify" (singular). Then, a search for gamification combined with "criticism," "downsides", and "negative" was performed. Second, we investigated the use of gamification in applications for the elderly population (see Multimedia Appendix 1), entering the following combinations of keywords: "gamification," "gamif*," "game," and "gaming" with "elder*," "elderly," "senior," "old*," and "aging." Finally, through the same search method, we have researched user classifications that categorize users by their motivation or stimulant to play in order to gain insight into the user and further determine how to tailor content to the user (see Multimedia Appendix 2). Keywords used were "[user, player, gamer]" combined with "[type, taxonomy, classification, model, style]."

Included in the results were articles and other works that present a theoretical basis for the development of gamification, defined as the presence of a framework that is either theoretical and/or based on established scientific foundations or proven effective through evaluation in practice. Therefore, beyond the scope of our paper are numerous works on gamified applications with a black box design.

\section{Results}

\section{Gamification Frameworks}

This section demonstrates the current state of gamification, starting with the concept of gamification in a broader sense and then focusing on gamification for elderly people. We provide an overview of existing frameworks for gamification along with their contexts and backgrounds. With this, we aim to define the status quo in research and provide a deeper understanding of the concept and its use and misuse.

\section{The Conceptualization of Gamification}

Gamification has gained popularity in diverse fields such as (interactive) marketing and scientific applications, generating different definitions of gamification. Currently, there is no consensus about a definition, mainly due to the underlying perception of what the game elements are exactly in terms of 
level of abstraction and whether the gamified application is game-like or not. Gamification is often roughly defined as the use of elements from games in nongame contexts; a more refined definition regards gamification as the identification of that which makes games captivating and engaging followed by the transfer of this knowledge to nongame contexts, increasing user enjoyment $[12,13]$. While some see gamification as a way to act upon psychological principles as certain game techniques do [14], others define gamification as applying gameful interaction or design with a specific intention without creating a full-fledged game [10] or as the process of improving a service

Table 1. Frameworks for gamification in business and academia.

\begin{tabular}{ll}
\hline Business & Academia \\
\hline Cunningham and Zichermann (2011) & Aparicio et al (2012) \\
Werbach and Hunter (2012) & Nicholson (2012) \\
Duggan (Badgeville, 2012) & Sakamoto et al (2012) \\
\hline
\end{tabular}

In business-oriented, or corporate, gamification, the number of successful initiatives, in terms of increased user engagement or revenue, that use gamification has been rapidly increasing in the past few years [16]. It is estimated that the market spend on gamification solutions will grow exponentially until 2016, and at that time $40 \%$ of the world's top market value companies will be using gamification $[17,18]$. In gamification for the marketing of consumer products, a well-known success story is that of Nike+ by Nike. This gamified running log app, currently used by 5 million players to track their daily exercise goals, caused revenues in the running category to increase by $30 \%$ in 2011 alone [19]. An example of successful enterprise gamification is that of software company SAP. After SAP launched a new, gamified version of their online employee and customer community platform, employee usage increased by $400 \%$ and community feedback by $96 \%$ [20]. Gamification appears to be more than a fad, illustrated by the existence and ongoing success of companies such as Badgeville [21,22], which provides a platform for gamification of enterprise applications and serves major companies such as Samsung, Deloitte, and Dell [23].

There are several authors within this business orientation, such as Cunningham and Zichermann [12], who provide guidelines for gamification by listing game elements and mechanics such as feedback, achievement, social engagement loops, reinforcement, and status, including practical examples. Werbach and Hunter [14] simplify gamification and consider it a tool for business strategy. Their method offers practical guidelines on how to dissect existing games and use them to gamify other applications. Although this approach lacks intricate game mechanics, gamification is used as a comprehensible tool, presenting game elements as a set of building blocks that, used together, can provide the gamified application.

However, the way gamification is applied in business context receives a lot of criticism as analysts estimate that the bigger part of current gamified applications will not meet their business objectives, mainly due to poor design [24]. Game designers criticize the Cunningham and Zichermann method, stating that with gameful experiences that support the value creation of the user [15]. In the middle of these definitions, we see gamification as the use of game elements that create a game-like experience in a nongame context without creating a full game.

We found a couple of approaches toward the conceptualization of gamification. One emerges from business practices, such as marketing, customer loyalty, and employee engagement; the other from academia and not sales driven, often specifically aiming to incorporate theories on motivation, engagement, and behavior change. Table 1 illustrates this division of the found articles by author, grouped according to their focus.

the mechanics presented do not contribute to a gameful experience [25,26]. Robertson [25] states that gamification turns into "pointsification" when game elements are simply stripped from games and placed in another application. With this, structural components of games are perceived and used elsewhere to function as core mechanics, ignoring the fact that these mechanics should be the inner workings of games. Bogost criticizes this practice using the term "exploitationware" in an article [26] and blog entry titled "Gamification is Bullshit" [27] and states that gamification disassociates the practice from games created for the sole purpose of making an easy profit. A design may be poor as well when it extensively uses external conditions or reinforcements, as known from operant conditioning [28]. These reinforcements often function as main mechanisms to manipulate behavior and usually present in the form of point and reward systems. A shift from intrinsic to extrinsic motivation can occur through offering external awards, known as the overjustification effect [29], which may lead to an early loss of interest of the user. The initial interest in the (gamified) activity may also disappear once the rewards are no longer, or insufficiently, offered [30], an effect called the "hedonic treadmill" [31]. From this we observe that the development of a good game design concept is often disappearing into the background in corporate gamification initiatives, while it is as essential for creating an engaging experience as it is for traditional games.

Scientific research from within academia, the second approach we distinguish, includes few frameworks on the theoretical foundations of gamification. Aparicio et al [32] developed a framework focusing on intrinsic motivation by incorporating concepts from self-determination theory [33]. According to this theory, intrinsic motivation can increase by satisfying the following psychological factors: competence, autonomy, and relatedness. The framework procedure tells us to (1) identify the main objective, (2) identify which intrinsically motivating factors should be included, (3) determine which game mechanics should be used according to these factors, and (4) evaluate the framework in its final application. Nicholson [34] presents a complex framework for meaningful gamification, integrating 
user-centered design [35] in combination with self-determination, situated motivational affordance [36], situational relevance [37], and universal design for learning [38]. From these core theories, Nicholson [34] suggests how to provide more intrinsically motivating gamification leading to meaningful engagement. Self-determination can be found along with the transtheoretical model of behavior change [39] in the framework of Sakamoto et al [40], describing a value-based framework. The authors present 5 core values (informative, empathetic, persuasive, economic, and ideological value) that, when used with other game mechanics, can be used to create attractive and intrinsically motivating gamification services.
Several differences between the frameworks from business and academia (Table 2) can be observed. The business frameworks are very concrete; they are simple, provide practical guidelines, and, most importantly, have proven their success in this context. In academia, gamification has not yet reached this state of maturity. The frameworks found on both sides are contradictory: those from academia are conceptual and complex and provide methods that are much more difficult to apply. Therefore, among these are no empirically supported frameworks showing their effectiveness in practice. The frameworks from business are simplified, therefore lacking depth, which may suffice for marketing purposes but possibly not for long-term goals needed for telemedicine applications.

Table 2. The contrast between business and academic frameworks.

\begin{tabular}{ll}
\hline Business & Academia \\
\hline Applied & Conceptual \\
Simplicity & Complexity \\
Practical guidelines & Methods inexplicit \\
Proven worthy in practice & Earlier stage of development, less empirical support \\
Lacking depth, oversimplified & Solid scientific foundation \\
Short-term engagement suffices & Aiming for durable motivation \\
Immensely popular & Mostly unknown \\
\hline
\end{tabular}

\section{Gamification for Elderly Users}

While gamification is gaining popularity in telemedicine [41], limited information was found on appropriate designs for engaging elderly users. Our search for gamification frameworks did not return any information on how to address the elderly users. We therefore present existing literature that describes explorations of designing gamification for this population group (Table 3). Gerling and Masuch [7] indicate that gamification holds significant potential for elderly users, particularly in gamifying physical and cognitive therapy. The authors state that the main challenge for developing such apps lies within the unfamiliarity of older adults with games, making it difficult to draw content from existing digital games. Link et al [42] face a similar challenge after examining a set of game mechanics (points, status, and badges) and concluding that these have the desired impact on youth but not on older adults.
By contrast, Minge et al [43] see gamification as an opportunity to decrease feelings of fear and frustration that elderly people have toward technology. However, the authors emphasize that success depends on careful design. For example, the study participants did not enjoy aspects of quantification and comparison, which are otherwise very common elements of games.

IJsselsteijn et al [44] also state that digital games hold significant positive potential for elderly users, including therapeutic value and social bonding. Elderly users are underrepresented as consumers of digital games because the games offered are not in line with their accessibility and usability demands or their interests and needs. Design requirements are needed to offer the elderly engaging content. According to IJsselsteijn et al [44], however, no empirical data are available on the categorization of elderly gamers that is necessary to do so, including how this would translate into game content.

Table 3. Overview of papers described.

\begin{tabular}{ll}
\hline Source & Topic \\
\hline IJsselsteijn et al (2007) [44] & Design opportunities for engaging games for elderly \\
Gerling et al (2011) [7] & Potential of gamification for engaging (frail) elderly \\
Minge et al (2011) [43] & Attitude of elderly toward gamification \\
Link et al (2014) [42] & Effect of game elements on motivation of elderly \\
\hline
\end{tabular}

\section{Classifying Users: Player Taxonomies}

User classification holds a key role in the development of tailored game content, as it gives thorough insight into the preferences that individuals or subgroups within a target group may have [45]. However, there are limited valid methods to describe people regarding their gaming preferences [32], and none were found for the elderly user in particular [44]. In this section, we discuss several approaches for classifying users in general, broadly divided into archetypes and reasons to play. Archetypes, player types [46,47] (Bartle, Marczewski), and 
gaming personality (types) [48] (Vandenberghe) describe the player characteristics while reasons to play, player motivation $[49,50]$ (Yee), and kinds of fun [51,52] (LeBlanc, Lazzaro) take motivating elements as a starting point. In Figure 1, these various approaches are visualized in a diagram. At the end of this section, we summarize and compare these user taxonomies in a chart.

Figure 1. Approaches to classify the user.

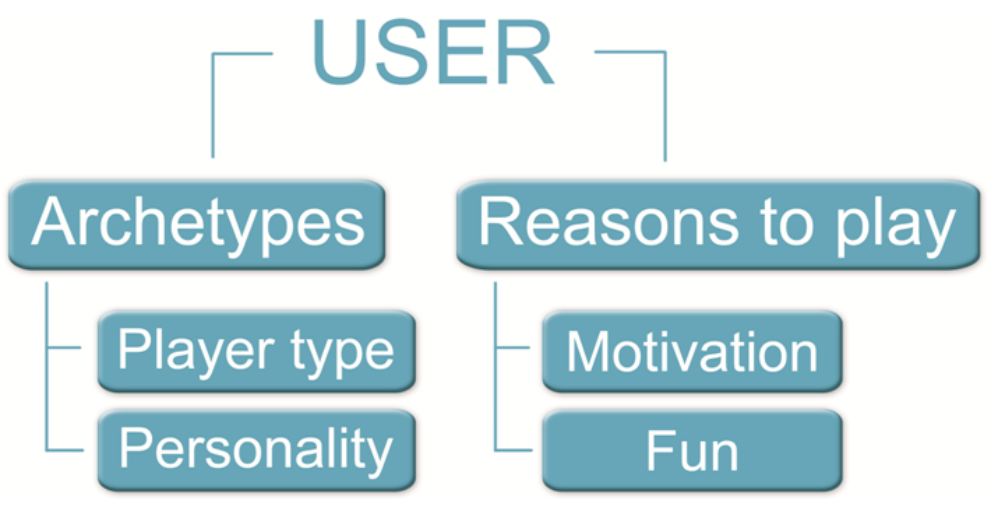

\section{Archetypes}

The earliest and most cited player taxonomy in a gaming context is the Bartle player type theory. It was developed for the first virtual multiuser environment, text-based dungeons (multiuser dungeons, or MUDs), by observing and analyzing player patterns. Bartle proposes 4 player types (Figure 2) based on two primary interests in gameplay: between the emphasis on players or on the environment and between acting (to) and interacting (with). Achievers are interested in actions on the world and find mastery of the game and competition most compelling; explorers like to interact with the world and enjoy discovery. Socializers are most interested in interacting with other players and enjoy the game for friendships and contacts, while killers are interested in acting on other players, demonstrating their superiority. According to Bartle, a good MUD contains the 4 player types in equilibrium [46] - not necessarily of equal number-and the player types were created to balance the design of these multiplayer games to accommodate for all player types' play style. The application of this model outside its context is something Bartle himself advises against [45], especially for use in gamification. Furthermore, this model has been criticized for lacking proper validation with empirical data and means to assess players to a type [53,49] and for missing similarity between the virtual world of the MUD and the gamified application. Bartle suggests that the types are exclusive but, in practice, they can be overlapping or mixing [12].

Similarly, but in the context of enterprise gamification, Marczewski [54] proposes a conceptual taxonomy choosing intrinsic motivations from different theories-autonomy; purpose and mastery; change - and the extrinsic motivation, rewards. This results in 6 player types (Figure 3). The axes are equal to the Bartle model but replace player for user and world for system.

Another approach to create player archetypes is through personality. Personality traits have been extensively studied and researched since the 1880s [55] and, although thousands of traits can be found to describe personality [56], a statistical factor analysis demonstrated 5 main factors that many psychologists believe are sufficient $[57,58]$. The five-factor model (FFM), or Big Five, is currently the most popular and has shown to be reputable, predictive (even normally distributed), reliable, crossculturally tested, and universal [59-63].

In the context of games and gaming, several attempts on predicting the effectiveness of the application of FFM showed inconsistent results $[64,65]$. In one study, personality traits have been related to preference for game genres [66]. A low predictive capability was found, which may be caused by a lack of evidence on whether the FFM is a valid method to measure personality in a game or not $[67,68]$; however, direct correlations between the FFM and gaming were researched and described by Vandenberghe [48]. He states that personality is very accurately predictive of gaming preferences and that people play with the same motivations they have in real life or look to express a particular part of personality that is unsatisfied in real life. In his model, the 5 domains of play, a translation of the original FFM traits is made into aspects of gaming motivation (Table 4). Each player is ranked on a linear scale on each of the 5 domains, thereby creating a character description rather than a categorization into a single player type. At the same time, the domains provide insight into the type of content that satisfies the player. 
Table 4. Five-factor model traits and corresponding gaming motivation traits (deduced from Vandenberghe [48]).

\begin{tabular}{lll}
\hline Low score & Trait & High score \\
\hline Cautious, predictable & Openness to experience & Inventive, curious \\
Repeating, conventional & Novelty & Open, imaginative experiences \\
Careless, impulsive & Conscientiousness & Efficient, organized \\
Low effort and self-control & Challenge & High effort and self-control \\
Reserved, solitary & Extraversion & Energetic, outgoing \\
Relaxing, low social engagement & Stimulation & Exciting, high social engagement \\
Analytical, detached & Agreeableness & Friendly, compassionate \\
Competition, defeating & Harmony & Cooperation, helping \\
Confident, secure & Neuroticism & Nervous, sensitive \\
Cheerful, comforting & Threat & Gloom, horror, high tension \\
\hline
\end{tabular}

Two examples illustrate specific gaming elements derived from motivation facets. First, the imagination of the user correlates with a preference for either fantasy or realism: someone who scores high on imagination will tend to prefer games that take place in exotic worlds, whereas someone with a low score will prefer games that take place in a world much like ours. Second,

Figure 2. Bartle's player type model.

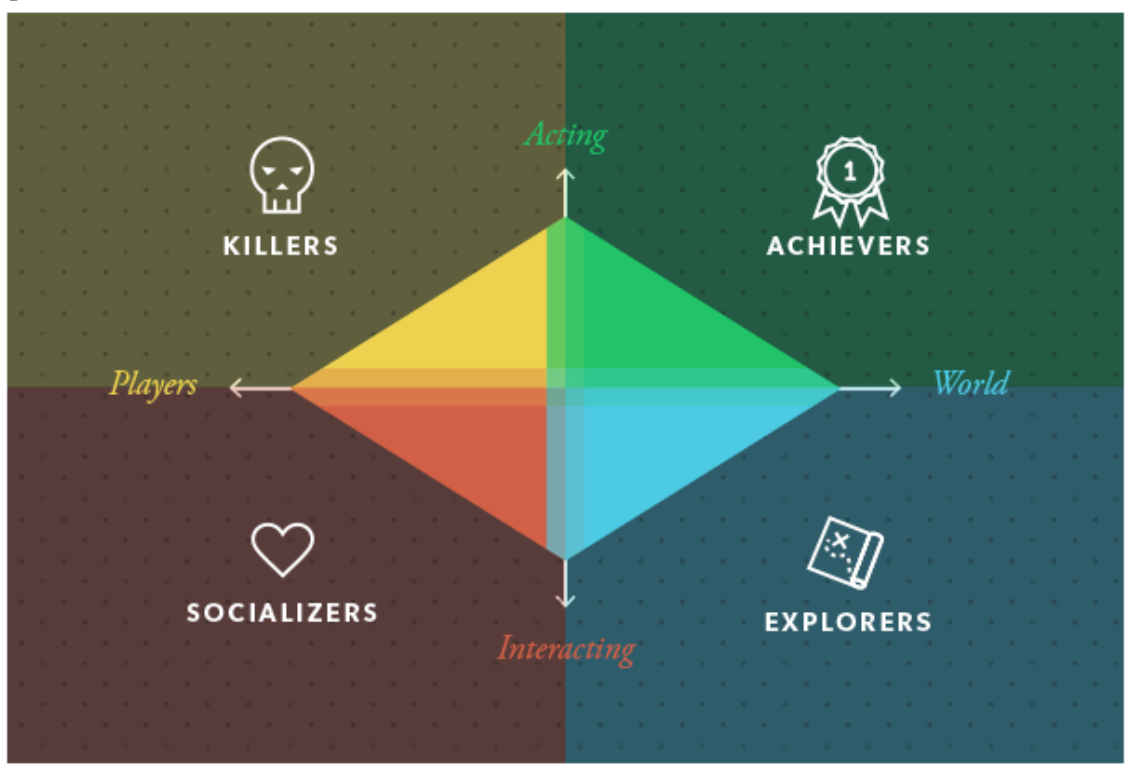

Figure 3. Marczewski's player type model.

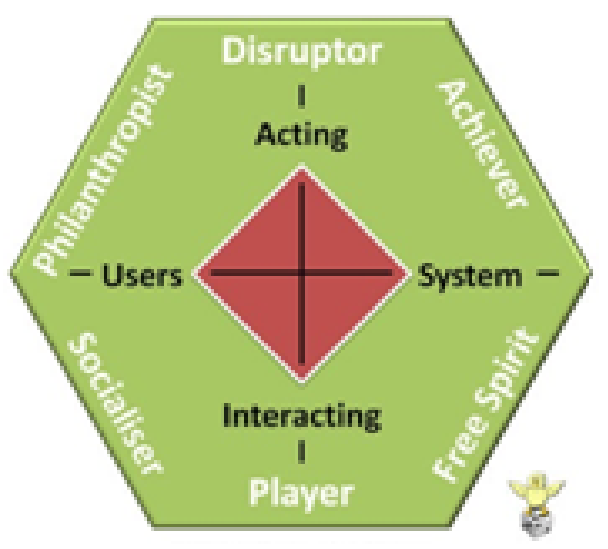




\section{Reasons to Play}

Yee [70] proposes a taxonomy based on users' reasons to play and used a long-term, qualitative analysis and factor analytical approach to create a taxonomy based on player motivations in MMORPGs (massive multiplayer online role-play games). The model by Yee consists of 10 subcomponents factored into 3 main components with which they are most correlated (Figure 4). Each subcomponent is linked to game elements from which players derive satisfaction. He finds that the killer must be omitted and merged into his component of achievement and the original explorer type must be divided into mechanics and discovery. The Yee model is similar to Bartle's but overcomes several of its weaknesses. For example, the components of Bartle types are not highly correlated, the types overlap and are not distinctive, and a practical way to assess users is lacking. However, similar to the Bartle typology is its narrow focus on massive online gaming.
A taxonomy of game aesthetics, or what makes a game fun, can be found in the mechanics, dynamics, and aesthetics framework by LeBlanc et al [51]. As much as 8 kinds of fun are defined: sensation, fantasy, narrative, challenge, fellowship, discovery, expression, and submission. These aesthetics are used to describe why certain players engage with certain games and more regard the game than categorize the player. Similarly, also focusing on fun as a reason to play, Lazzaro [52] conducted a study to clarify how to address emotions in games without using a storyline by learning what (adult) players found were good gaming experiences. The "4 keys" to fun are

- Hard fun: players like challenge, strategy, problem solving, experiencing frustration.

- Easy fun: players like intrigue and curiosity and enjoy immersion.

- Altered states: players search for internal sensations such as excitement.

- The people factor: players use games for social experiences.

Figure 4. Yee's model motivations of play in MMORPGs: the components and subcomponents.

\begin{tabular}{|c|c|c|}
\hline Achievement & Social & Immersion \\
\hline Advancement & Socializing & Discovery \\
Progress, Power, & Casual Chat, Helping Others, & Exploration, Lore, \\
Accumulation, Status & Making Friends & Finding Hidden Things \\
\hline Mechanics & Relationship & Role-Playing \\
Numbers, Optimization, & Personal, Self-Disclosure, & Story Line, Character History, \\
Templating, Analysis & Find and Give Support & Roles, Fantasy \\
\hline Competition & Teamwork & Customization \\
\hline Challenging Others, & Collaboration, Groups, & Appearances, Accessories, \\
Provocation, Domination & Group Achievements & Style, Color Schemes \\
\hline & & Escapism \\
& & Relax, Escape from RL, \\
& & Avoid RL Problems \\
\hline
\end{tabular}

\section{Overview of Taxonomies}

Although the taxonomies aforementioned appear very different concerning the types of classes, many parallels can be found between the characteristics of each class. We present the results in an overview chart (Figure 5). The top row in gray shows the author of the model, and under each author the defined classes (types, motivations, facets, etc) are shown. Arrows indicate a direct derivative of a model, as explained in the previous section; black lines indicate which classes show highly similar characteristics. The dotted line indicates that classes only have several characteristics in common. The colors indicate which classes belong to the same group. This overview shows that there is great connectivity between the models and highlights that the model of Vandenberghe covers all class properties of the other models (except for the player in the Marczewski model).

In the models of Marczewski and Yee, which both have Bartle as point of reference, we see a clear analogy between the achievers and socializers and also in the attributes of the free spirit (interacting with the system, autonomy), the explorer (interacting with the world), and immersion (discovery, exploration). Although Yee does not have a separate type for the killer or disruptor, provocation and domination are present in achievement. Linking to Lazzaro and LeBlanc, achievement is similar to the concept of hard fun and challenge; easy fun (which includes the motive of immersion) and discovery are similar to exploring; and the people factor and fellowship and expression relate to the social aspect. The model of Vandenberghe not only seems all-embracing, but it also adds a dimension to each personality trait. The killer can be linked to a very low score on harmony, the achiever to a high score on challenge, the explorer to a high score on novelty, the socializer to a high score on stimulation. The trait threat is quite unique and only linked to submission. According to Vandenberghe, this trait may not be pointing out what keeps a player playing but what makes the player decide to stop playing.

None of the taxonomies presented target the elderly user specifically. Furthermore, we do not know of any methods regarding the mapping of this target group on the existing taxonomies, mainly because the gaming industry does not focus on this group as a consumer for video games. Moreover, the 
taxonomies are in most cases designed for use in a specific application, such as enterprise gamification or MMORPGs, and it is not known how suitable they are for application in telemedicine interventions. We can identify many parallels between the models, and we consider that the 5 domains of play stand out from the rest. Unlike the other models, an individual is not given a singular class label or a combination of those. Instead, a complete character description can be created based on preference for certain aspects or elements of games. What makes this theory even more attractive is that it describes the user based on personality, a universal understanding regardless of age.

Figure 5. Chart of connections between taxonomies (arrow: direct derivative of, line: high similarity in concept, dots: closely related concepts).

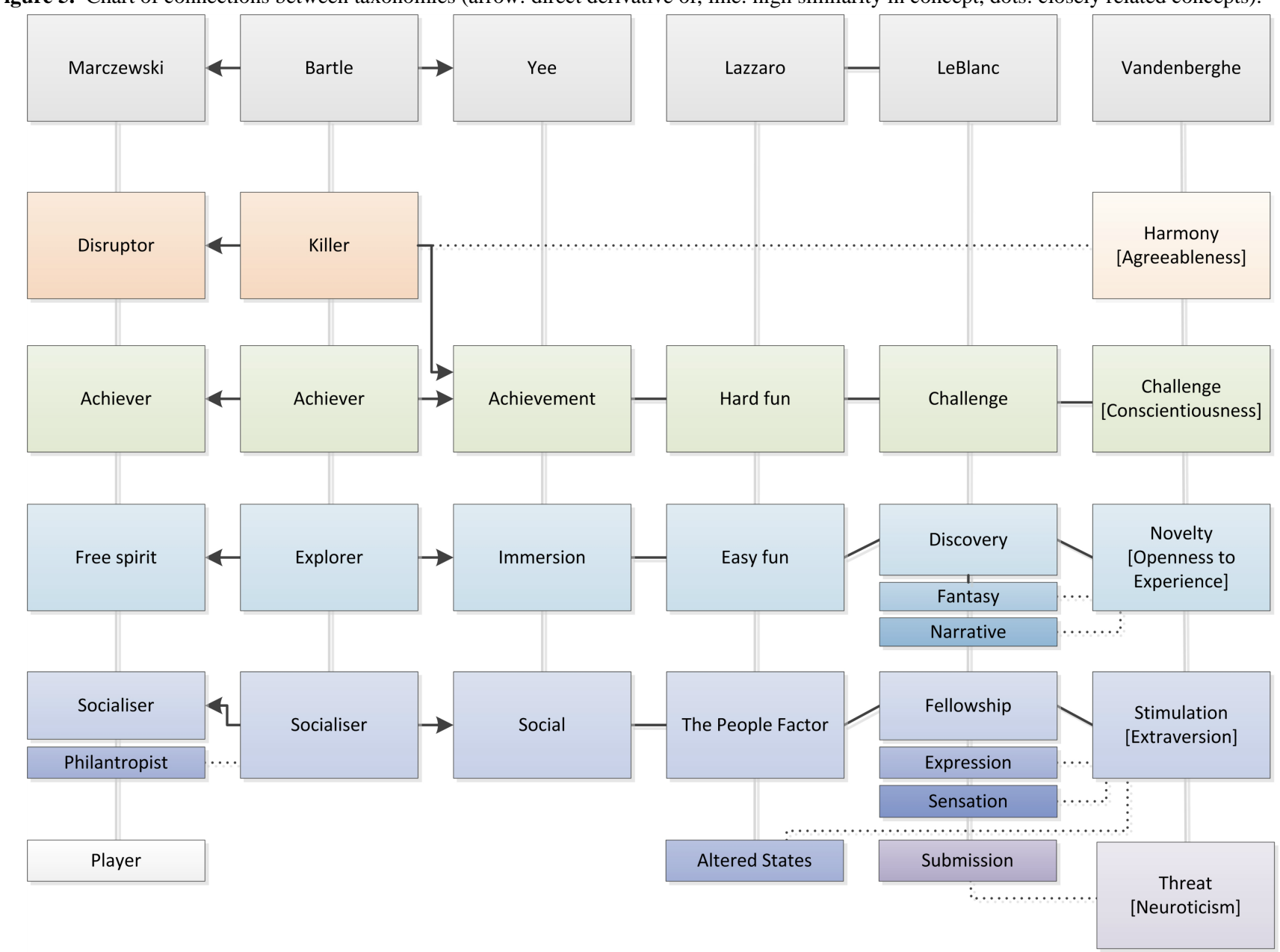

\section{Discussion}

\section{Principal Findings}

The first objective of this study was to provide an overview of theoretical frameworks for the application of gamification and of methods for gamification that specifically target the elderly user. Second, we have explored user classification theories, which are needed to gain insight into the user and serve as a tool to effectively tailor content. We have found that current frameworks for gamification rarely target the elderly user. The effectiveness of the use of user classifications for tailored game content is not yet known, neither are there indications for classifying the elderly user with these theories. How can we use these results to systematically design effective gamified telemedicine applications for elderly?

Frameworks for gamification emerge from two main approaches. First, there is a business-oriented approach, with examples of success in practice, using an easy-to-apply framework to gamify applications. However, the frameworks from this approach may also be oversimplified, which suffices for marketing purposes but possibly not for long-term engagement needed in telemedicine. Second, frameworks created within academia target for higher causes, such as better education and health outcomes. These frameworks often make use of established theories but are complex, and, at the time of writing, not used in practice. In both approaches, no appropriate framework was found to design gamification for elderly users and application in telemedicine. Therefore, a new framework should be created that is of sufficient depth but applicable in practice and supported by empirical data on its effectiveness. To do so, we would position our future research in academia and take example of the studies presented within this approach. Just like the authors discussed $[32,34,40]$, we would aim for qualitative, long-term engagement and focus on stimulating intrinsic motivation.

Our study showed two approaches for user classification theories: archetypes, where classes are user types with associated preferences, and reasons to play, where classes are based on attributes that describe the user preference. None of the found 
taxonomies seem to be applicable in telemedicine for elderly users due to the very different context and audience for which they have been developed and the fact that we are not familiar with the use of these taxonomies in practice. However, a high level of understanding of the target group will greatly contribute to designing effectively engaging content. This can be achieved by a taxonomy for game design specifically for elderly users. Creating such a taxonomy and corresponding game content can be difficult, because older adults may relate to video games differently than younger users as they might not be able to draw from earlier experience with video games. To create such a classification, it would be most desirable to observe the behavior of intended users in games, but the scarcity of elderly gamers (and limited availability of games for elderly people) does not provide sufficiently representative subjects for the whole target group.

Although from the taxonomies found none seem directly suitable for creating our future framework, the 5 domains of the play model [48] exceed the stereotypical classes of the other models by providing a detailed insight and overview of motivations users may have. The model provides an overview of both player and preferences (where others use, for example, game genres, which are ambiguous, not clearly outlined, and differing for each producer of video games) and is moreover based on a universally applicable psychological concept that may help in overcoming the particular challenge of mapping a group of users onto a taxonomy who have not been exposed to games at a young age. Therefore, we believe the model by Vandenberghe advances on earlier classifications, thus making it unique and worthwhile to explore further for use in game design for elderly users.

Advantages of creating a framework within the academic approach are the possibility of using solid scientifically established theories and incorporating existing motivational theories and instruments that relate to the objective of gamification to motivate and engage. Serious games and exergames for elderly users [71,72] were not included in our study because our present focus is on improving adherence to existing health interventions by means of gamification, and serious games are full games that require a different approach. However, gamification in persuasive (game) design [73-75] or vice versa and gamification for behavior change [76] [77] deserve to be explored. Furthermore, because a well-designed game concept is essential for creating a motivating experience for the user, relevant game design principles that consider the aspect of experience on engagement such as flow [78,79], immersion [50], and customization [8] can prove useful in reaching our goals. Furthermore, we emphasize the necessity of a good game design concept to successfully gamify an application for engagement. The framework we aim to develop in the future should always leave room for the creative process that is involved. We may be able to predict the preference of a user for different types of content but how content is then designed according to these preferences to appeal to the player could be more art than science.

\section{Conclusion}

We suggest developing a framework for gamification that is based on solid scientific foundations and includes a user classification that specifically assesses the elderly user. We base this classification on the 5 domains of the play model that predicts the existence of a relation between preference for game content and personality. In a study, we need to explore this relation as well as opportunities for use for the intended target group and context. When we know more of these aspects, a gamification framework can be developed by which the classification of the elderly user is used to effectively create tailored, engaging game content. Subsequently, the framework needs to be put to practice and evaluated for empirical support of its effectiveness.

\section{Acknowledgments}

This work is part of the PERSSILAA project [80] and the MAGGY project [81]. PERSSILAA (Personalised ICT Supported Service for Independent Living and Active Ageing) is sponsored by the EU (FP7-ICT-2013-10). MAGGY (Mobile Activity Game for Elderly) is sponsored by the Netherlands Organization for Scientific Research (NWO), Creative Industry Program (314-99-002).

\section{Conflicts of Interest}

None declared.

\section{Multimedia Appendix 1}

Keywords first search.

[PDF File (Adobe PDF File), 8KB-Multimedia Appendix 1]

\section{Multimedia Appendix 2}

Keywords second search.

[PDF File (Adobe PDF File), 6KB-Multimedia Appendix 2]

\section{References}


1. WHO. World Health Organization. Healthy ageing URL: http://www.euro.who.int/en/health-topics/Life-stages/healthy-ageing/ healthy-ageing [accessed 2015-04-20] [WebCite Cache ID 6XvRTikMB]

2. Przywara B. Economic Papers 417. 2010. Projecting future health care expenditure at European level: drivers, methodology and main results URL: http://ec.europa.eu/economy_finance/publications/economic_paper/2010/pdf/ecp417_en.pdf [accessed 2014-04-04] [WebCite Cache ID 6XvT7h8Ig]

3. Jansen-Kosterink S. The added value of telemedicine services for physical rehabilitation. Enschede: University of Twente; 2014.

4. Tabak M, Brusse-Keizer M, Valk, Van der P, Hermens H, Vollenbroek-Hutten M. A telehealth program for self-management of COPD exacerbations and promotion of an active lifestyle: a pilot randomized controlled trial. International Journal of COPD 2014:935-944. [doi: 10.2147/COPD.S60179]

5. Evering R. Ambulatory Feedback at Daily Physical Activity Patterns: A Treatment for the Chronic Fatigue Syndrome in the Home Environment?. Enschede: University of Twente; 2013.

6. Huis in 't Veld R, Kosterink S, Barbe T, Lindegård A, Marecek T, Vollenbroek-Hutten M. Relation between patient satisfaction, compliance and the clinical benefit of a teletreatment application for chronic pain. J Telemed Telecare 2010;16(6):322-328. [doi: 10.1258/jtt.2010.006006] [Medline: 20798426]

7. Gerling K, Masuch M. Exploring the potential of gamification among frail elderly persons. CHI 2011 Work Gamification Using Game Des 2011.

8. Bakkes S, Tan C, Pisan Y. Personalised Gaming: A Motivation and Overview of Literature. 2012 Presented at: Proc 8th Australas Conf Interact Entertain Play Syst '12; 2012; New York. [doi: 10.1145/2336727.2336731]

9. Cordova D, Lepper M. Intrinsic motivation and the process of learning: Beneficial effects of contextualization, personalization, and choice. Journal of Educational Psychology 1996 Oct 1;88(4):715-730. [doi: 10.1037/0022-0663.88.4.715]

10. Deterding S, Dixon D, Khaled R, Nacke L. From game design elements to gamefulness. 2011 Presented at: Proc 15th Int Acad MindTrek Conf Envisioning Futur Media Environ - MindTrek '11; 2011; Tampere, Finland p. 9-11. [doi: $\underline{10.1145 / 2181037.2181040]}$

11. Werbach K. Gamification (University of Pennsylvania).: Coursera URL: https://www.coursera.org/course/gamification [accessed 2015-11-24] [WebCite Cache ID 6dHJKk9tz]

12. Zichermann G, Cunningham C. Gamification By Design. In: Gamification by Design: Implementing Game Mechanics in Web and Mobile Apps. CA: O'Reilly Media; 2011.

13. Malone T. Heuristics for designing enjoyable user interfaces: Lessons from computer games. 1982 Presented at: Proc Conf Hum factors Comput Syst; 1982; Maryland, US p. 63-68. [doi: 10.1145/800049.801756]

14. Werbach K, Hunter D. For the Win: How Game Thinking Can Revolutionize Your Business. Pennsylvania: Wharton Digital Press; 2012.

15. Huotari K. Defining Gamification - A Service Marketing Perspective. 2012 Presented at: Proc 15th Int Acad MindTrek Conf Envisioning Futur Media Environ; 2012; Tampere p. 17-22. [doi: 10.1145/2393132.2393137]

16. Chou Y. 2015. A comprehensive list of 90+ gamification cases with ROI stats URL: http://www.yukaichou.com/ gamification-examples/gamification-stats-figures/ [accessed 2015-07-22] [WebCite Cache ID 6aDet6OK9]

17. Gartner inc. 2012. Gartner Reveals Top Predictions for IT Organizations and Users for 2013 and Beyond URL: http://www. gartner.com/newsroom/id/2211115 [accessed 2015-07-22] [WebCite Cache ID 6aDfacKwr]

18. Meloni W, Gruener W. Gamification in 2012. URL: http://gamingbusinessreview.com/wp-content/uploads/2012/05/ Gamification-in-2012-M2R3.pdf [accessed 2015-11-24] [WebCite Cache ID 6dHK7Om4n]

19. Ryan M, Sleigh A, Soh K. Why gamification is serious business. 2015. URL: https://www.accenture.com/za-en/ insight-outlook-why-gamification-is-serious-business.aspx [accessed 2015-07-22] [WebCite Cache ID 6aDg6JUQB]

20. Cetin L. The SAP Community Network. 2013. How to Use Gamification to Increase Engagement URL: http://www. enterprise-gamification.com/index.

php?option=com content\&view=article\&id=160:the-sap-community-network-how-to-use-gamification-to-increase-engagement\&catid=15\&ltemid=22\&lang=en[WebCite Cache ID 6aDgGbApu]

21. Zichermann G. Gamification: The Hard Truths. 2013. URL: http://www.huffingtonpost.com/gabe-zichermann/ gamification b 2516376.html [accessed 2015-07-22] [WebCite Cache ID 6aDgMo6Pa]

22. Takahashi D. Badgeville's Kris Duggan: Six frameworks can gamify employee and customer engagement (interview). 2012. URL: http://venturebeat.com/2012/05/30/badgeville-kris-duggan-interview/ [accessed 2015-04-20] [WebCite Cache ID 6XvUlxjlW]

23. Badgeville: The \#1 Gamification Platform for the Enterprise. URL: https://badgeville.com/ [accessed 2015-04-20] [WebCite Cache ID 6XvUyaDmQ]

24. Gartner I. Gartner Says by 2014, 80 Percent of Current Gamified Applications Will Fail to Meet Business Objectives Primarily Due to Poor Design. 2012. URL: http://www.gartner.com/newsroom/id/2251015 [accessed 2015-07-22] [WebCite Cache ID 6aDgYji3Z]

25. Robertson M. Can't play, won't play - Blog: Hide\&Seek. 2010. URL: http://hideandseek.net/2010/10/06/cant-play-wont-play [accessed 2015-04-20] [WebCite Cache ID 6XvYdsA2p] 
26. Bogost I. 2011. Persuasive Games: Exploitationware - Gamasutra URL: http://www.gamasutra.com/view/feature/134735/ persuasive games exploitationware.php [accessed 2015-04-20] [WebCite Cache ID 6XvYoDaCI]

27. Bogost I. 2011. Gamification is Bullshit Internet URL: http://bogost.com/writing/blog/gamification is bullshit/ [accessed 2015-04-20] [WebCite Cache ID 6XvZ0UBql]

28. Skinner B. The behavior of organisms: an experimental analysis. Oxford: Appleton-Century; 1938.

29. Lepper MR, Greene D, Nisbett RE. Undermining children's intrinsic interest with extrinsic reward: A test of the "overjustification" hypothesis. Journal of Personality and Social Psychology 1973;28(1):129-137. [doi: 10.1037/h0035519]

30. Carlson N, Miller H, Heth C, Donahoe J. Psychology: The Science of Behavior, Books a la Carte Plus MyPsychLab (7th Edition) (Books a la Carte Plus: MyPsychLab). New Jersey: Prentice Hall; 2010.

31. Brickman P, Campbell D. Hedonic relativism and planning the good society. Adapt theory a Symp 1971;287:302.

32. Aparicio A, Vela F, Sánchez J, Montes J. Analysis and application of gamification. 2012 Presented at: Proc 13th Int Conf Interacción Pers - INTERACCION '12; 2012; Spain p. 1-2. [doi: 10.1145/2379636.2379653]

33. Deci E, Ryan R. Intrinsic motivation and self-determination in human behavior. New York: Plenum; 1985.

34. Nicholson S. A User-Centered Theoretical Framework for Meaningful Gamification A Brief Introduction to Gamification Organismic Integration Theory Situational Relevance and Situated Motivational Affordance. Games Learning Society 8.0 2012.

35. Norman D. The design of everyday things. In: The design of everyday things. New York: Basic Books, $2002 ; 1988$.

36. Deterding S. Situated motivational affordances of game elements: A conceptual model. In: CHI 2011 conf proceedings. 2011 Presented at: CHI 2011; May 7-12 2011; Vancouver.

37. Wilson P. Situational relevance. Information Storage and Retrieval 1973 Aug;9(8):457-471. [doi: 10.1016/0020-0271(73)90096-X]

38. Rose D, Meyer A. Teaching every student in the Digital Age: universal design for learning. Alexandria, Va: Association for Supervision and Curriculum Development; 2002.

39. Prochaska J, Marcus B. The transtheoretical model: Applications to exercise. Adv Exerc adherence. - 1994;161:80.

40. Sakamoto M, Nakajima T, Alexandrova T. Value-based design for gamifying daily activities. Lect Notes Comput Sci. LNCS. ISBN 2012;7522:421-424. [doi: 10.1007/978-3-642-33542-6 43]

41. Tabak M, Dekker-van Weering M, Dijk, van H, Vollenbroek-Hutten M. Promoting Daily Physical Activity by Means of Mobile Gaming: A Review of the State of the Art. Games Health J 2015 Dec;4(6):460-469. [doi: 10.1089/g4h.2015.0010] [Medline: 26397179]

42. Link M, Lai J, Bristol K. Not So Fun? The Challenges of Applying Gamification to Smartphone Measurement. DUXU 2014 part IV 2014;319:27.

43. Minge M, Bürglen J, Cymek D. Exploring the Potential of Gameful Interaction Design of ICT for the Elderly. Commun Comput Inf Sci. PART I(2004) 2014;435:304-309. [doi: 10.1007/978-3-319-07854-0 54]

44. IJsselsteijn W, Nap H, de Kort Y, Poels K. Digital Game Design for Elderly Users. 2007 Presented at: Proc Conf Futur Play; 2007; Toronto p. 17-22. [doi: 10.1145/1328202.1328206]

45. Bartle R. Player Type Theory: Uses and Abuses. 2012. URL: http://youtu.be/ZIzLbE-93nc [accessed 2015-04-20] [WebCite Cache ID 6XvZUrAVZ]

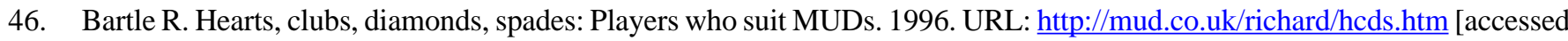
2015-04-20] [WebCite Cache ID 6XvZlirzF]

47. Marczewski A. A New Perspective on the Bartle Player Types for Gamification. 2012. URL: http://www.gamification.co/ 2013/08/12/a-new-perspective-on-the-bartle-player-types-for-gamification/ [accessed 2015-04-20] [WebCite Cache ID $\underline{6 \mathrm{XvZuwUtK}]}$

48. Vandenberghe J. The 5 Domains of Play: Applying Psychology's Big 5 Motivation Domains to Games. 2012. URL: http:/ /www.gdcvault.com/play/1015364/The-5-Domains-of-Play [accessed 2015-04-20] [WebCite Cache ID 6Xva2AWDK]

49. Yee N. Motivations of play in MMORPGs. 2005 Presented at: Proc DiGRA Conf Chang Views - Worlds Play; 2005; Vancouver.

50. Przybylski A, Rigby C, Ryan R. A motivational model of video game engagement. Review of General Psychology 2010;14(2):154-166. [doi: 10.1037/a0019440]

51. Hunicke R, LeBlanc M, Zubek R. MDA: A Formal Approach to Game DesignGame Research. Work Challenges Game AI. - 2004;1:4.

52. Lazzaro N. Why We Play Games: Four Keys to More Emotion Without Story. Game Dev Conf 2004.

53. Dixon D. Player Types and Gamification. In: Proceedings of the CHI 2011 Workshop on Gamification. 2011 Presented at: CHI; 2011; Vancouver.

54. Marczewski A. A User Type Framework for Gamification Design. 2013. URL: http://www.gamified.uk/user-types/ [accessed 2015-04-20] [WebCite Cache ID 6XvcmkQ9e]

55. Tredoux G. Francis Galton as Anthropologist. URL: http://galton.org/anthropologist.htm [accessed 2015-04-20] [WebCite Cache ID 6XvdOIx8n]

56. Allport G. Personality: a psychological interpretation. Am J Sociol 1937;45(1):120-123. 
57. McCrae RR, Costa PT. Validation of the five-factor model of personality across instruments and observers. J Pers Soc Psychol 1987 Jan;52(1):81-90. [Medline: 3820081]

58. Costa J. PT, McCrae RR. Four ways five factors are basic. Pers individ Diff 1991;13(6):653-665.

59. Bouchard TJ, Loehlin JC. Genes, evolution, and personality. Behav Genet 2001 May;31(3):243-273. [Medline: 11699599]

60. Gurven M, von Rueden C, Massenkoff M, Kaplan H, Lero Vie M. How universal is the Big Five? Testing the five-factor model of personality variation among forager-farmers in the Bolivian Amazon. J Pers Soc Psychol 2013 Feb;104(2):354-370 [FREE Full text] [doi: 10.1037/a0030841] [Medline: 23245291]

61. McCrae RR. Cross-Cultural Research on the Five-Factor Model of Personality. Online Readings in Psychology and Culture 2002 Aug 01;4(4). [doi: 10.9707/2307-0919.1038]

62. McCrae RR, Terracciano A, Personality Profiles of Cultures Project. Universal features of personality traits from the observer's perspective: data from 50 cultures. J Pers Soc Psychol 2005 Mar;88(3):547-561. [doi: 10.1037/0022-3514.88.3.547] [Medline: 15740445$]$

63. Schmitt D, Allik J, McCrae R, Benet-Martinez V. The Geographic Distribution of Big Five Personality Traits: Patterns and Profiles of Human Self-Description Across 56 Nations. Journal of Cross-Cultural Psychology 2007 Mar 01;38(2):173-212. [doi: 10.1177/0022022106297299]

64. Orji R, Vassileva J, Mandryk RL. Modeling the efficacy of persuasive strategies for different gamer types in serious games for health. User Model User-Adap Inter 2014 Jul 14;24(5):453-498. [doi: 10.1007/s11257-014-9149-8]

65. Borders J. Relationship Between Personality and Video Game Preferences. Thesis 2012.

66. Zammitto V. Game research, measuring gaming preferences. Appl Artif Intell 2009:15-16. [doi: 10.1145/1639601.1639611]

67. Zammitto V. Gamers' Personality and their Gaming Preferences. Sch Interact Arts Technol;M.Sc Thesi $2010: 147$.

68. Teng C. Online Game Player Personality and Real-life Need Fulfillment. Int J Cyber Soc Educ 2009;2(2):39-50.

69. Despain W. 100 Principles of Game Design. In: New Riders. Boston: Pearson Education; 2013:-321.

70. Yee N. Motivations for play in online games. Cyberpsychol Behav 2006 Dec;9(6):772-775. [doi: 10.1089/cpb.2006.9.772] [Medline: $\underline{\text { 17201605] }}$

71. Fua K, Gupta S, Pautler D, Farber L. Designing Serious Games for Elders. 2013 Presented at: Proc Int Conf Found Digit Games; 2013; Chania, Greece p. 291-297.

72. Brauner P, Calero VA, Schroeder U, Ziefle M. Increase Physical Fitness and Create Health Awareness through Exergames and Gamification. The Role of Individual Factors, Motivation and Acceptance. In: Proc SouthCHI 2013, LNCS 7946. 2013 Presented at: SouthCHI 2013; 2013; Slovenia p. 62-63. [doi: 10.1007/978-3-642-39062]

73. Fogg B. A behavior model for persuasive design. 2009 Presented at: Proc 4th Int Conf Persuas Technol - Persuas '09; 2009; California. [doi: 10.1145/1541948.1541999]

74. Oinas-kukkonen H, Harjumaa M. Persuasive Systems Design: Key Issues, Process Model, and System Features. Commun Assoc Inf Syst 2009;24(28):485-500.

75. Kelders SM, Kok RN, Ossebaard HC, Van Gemert-Pijnen Julia E W C. Persuasive system design does matter: a systematic review of adherence to web-based interventions. J Med Internet Res 2012;14(6):e152 [FREE Full text] [doi: 10.2196/jmir.2104] [Medline: 23151820]

76. Cugelman B. Gamification: what it is and why it matters to digital health behavior change developers. JMIR Serious Games 2013;1(1):e3 [FREE Full text] [doi: 10.2196/games.3139] [Medline: 25658754]

77. Consolvo S, McDonald D, Landay J. Theory-driven design strategies for technologies that support behavior change in everyday life. In: 27th Int Conf Hum factors Comput Syst. 2009 Presented at: CHI 2009; 2009; Boston p. 405-414. [doi: 10.1145/1518701.1518766]

78. Csikszentmihalyi M. Acad Manag Rev. In: Flow: the psychology of optimal experience. New York: HarperPerennial; 1990.

79. Schell J. Chapter: The Flow Channel. In: The art of game design: a book of lenses. San Francisco: Morgan Kaufmann; 2008.

80. PERSSILAA: Personalised ICT Supported Service for Independent Living and Active Ageing. URL: https://www.perssilaa. eu [accessed 2015-12-08] [WebCite Cache ID 6dchXhAfq]

81. MAGGY: Mobile Activity Game for Elderly. URL: http://www.maggygame.nl/ [accessed 2015-12-08] [WebCite Cache ID 6dchqNdu5]

\section{Abbreviations}

FFM: five-factor model

ICT: information communication technology

MMORPG: massive multiplayer online role-play games

MOOC: massive open online course

MUD: multiuser dungeon 
Edited by G Eysenbach; submitted 20.04.15; peer-reviewed by H Van Dijk, J Lumsden; comments to author 07.05.15; revised version received 30.07.15; accepted 30.09.15; published 18.12 .15

Please cite as:

de Vette F, Tabak M, Dekker - van Weering M, Vollenbroek-Hutten M

Engaging Elderly People in Telemedicine Through Gamification

JMIR Serious Games 2015;3(2):e9

URL: http://games.jmir.org/2015/2/e9/

doi: 10.2196/games.4561

PMID: 26685287

CFrederiek de Vette, Monique Tabak, Marit Dekker - van Weering, Miriam Vollenbroek-Hutten. Originally published in JMIR Serious Games (http://games.jmir.org), 18.12.2015. This is an open-access article distributed under the terms of the Creative Commons Attribution License (http://creativecommons.org/licenses/by/2.0/), which permits unrestricted use, distribution, and reproduction in any medium, provided the original work, first published in JMIR Serious Games, is properly cited. The complete bibliographic information, a link to the original publication on http://games.jmir.org, as well as this copyright and license information must be included. 